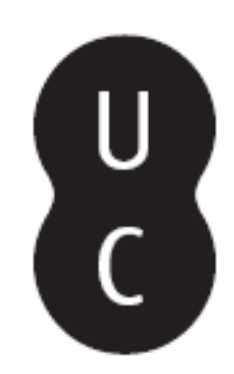

\title{
imp partillim
}

Os cegos precipícios: Friedrich Schiller
Autor(es): $\quad$ Barroso, Maria do Sameiro
Publicado por: Associação Portuguesa de Estudos Clássicos; Instituto de Estudos Clássicos

URL persistente:

URI:http://hdl.handle.net/10316.2/30450

DOI:

DOI:http://dx.doi.org/10.14195/0872-2110_51_14

Accessed : $\quad$ 26-Apr-2023 14:56:55

A navegação consulta e descarregamento dos títulos inseridos nas Bibliotecas Digitais UC Digitalis, UC Pombalina e UC Impactum, pressupõem a aceitação plena e sem reservas dos Termos e Condições de Uso destas Bibliotecas Digitais, disponíveis em https://digitalis.uc.pt/pt-pt/termos.

Conforme exposto nos referidos Termos e Condições de Uso, o descarregamento de títulos de acesso restrito requer uma licença válida de autorização devendo o utilizador aceder ao(s) documento(s) a partir de um endereço de IP da instituição detentora da supramencionada licença.

Ao utilizador é apenas permitido o descarregamento para uso pessoal, pelo que o emprego do(s) título(s) descarregado(s) para outro fim, designadamente comercial, carece de autorização do respetivo autor ou editor da obra.

Na medida em que todas as obras da UC Digitalis se encontram protegidas pelo Código do Direito de Autor e Direitos Conexos e demais legislação aplicável, toda a cópia, parcial ou total, deste documento, nos casos em que é legalmente admitida, deverá conter ou fazer-se acompanhar por este aviso.

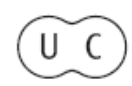




\section{Boletim de}

\section{Estudos Clássicos}

Associação Portuguesa de Estudos Clássicos Instituto de Estudos Clássicos

Coimbra

Junho de 2009 


\section{OS Cegos PRECIPÍCIOS FRIEDRICH SCHILLER}

\section{Der Ring des Polykrates}

Er stand auf seines Daches Zinnen, Er schaute mit vergnügten Sinnen Auf das beherrschte Samos hin. Dies alles ist mir untertänig, Begann er zu Egyptens König, Gestehe, daß ich glücklich bin.

Du hast der Götter Gunst erfahren! Die vormals deines Gleichen waren, Sie zwingt jetzt deines Szepters Macht. Doch einer lebt noch, sie zu rächen, Dich kann mein Mund nicht glücklich sprechen, So lang des Feindes Auge wacht.

Und eh' der König noch geendet, Da stellt sich, von Milet gesendet, Ein Bote dem Tyrannen dar:

Laß Herr! des Opfers Düfte steigen, Und mit des Lorbeers muntern Zweigen Bekränze dir dein festlich Haar.

Getroffen sank dein Feind vom Speere, Mich sendet mit frohen Märe, Dein treuer Feldherr Polydor Und nimmt aus einem schwarzen Becken Noch blutig, zu der beiden Schrecken, Ein wohlbekanntes Haupt hervor. 
Der König tritt zurück mit Grauen:

»Doch warn' ich dich, dem Glück zu trauen,

Versetzt er mit besorgtem Blick.

Bedenk', auf ungetreuen Wellen,

Wie leicht kann sie der Sturm zerschellen,

Schwimmt deiner Flotte zweifelnd Glück.«

Und eh' er noch das Wort geprochen,

Hat inh der Jubel unterbrochen,

Der von der Reede jauchzend schallt.

Mit fremden Schätzen reich beladen

Kehrt zu den heimischen Gestaden

Der Schiffe mastenreicher Wald.

Der königliche Gast erstaunet:

Dein Glück ist heute gut gelaunet,

Doch fürchte seinen Unbestand.

Der Kreter waffenkund'ge Scharen

Bedräuen dich mit Kriegsgefahren,

Schon nahe sind sie diesem Strand.

Und eh' ihm noch das Wort entfallen,

Da sieht ma's von den Schiffen wallen,

Und tausend Stimmen rufen: Sieg!

Von Feindesnot sind wir befreiet,

Die Kreter hat der Sturm zerstreuet,

Vorbei, geendet ist der Krieg.

Das hört der Gastfreund mit Entsetzen:

»Fürwahr, ich muß dich glücklich schätzen,

Doch, spricht er, zittr' ich für dein Heil.

Mir grauet vor der Götter Neide,

Des Lebens ungemischte Freude

Ward keinem Irdischen zu Teil.

Auch mir ist alles wohl geraten,

Bei allen meinen Herrschertaten

Begleit mich des Himmels Huld, 
Doch hatt' ich einen teuren Erben, Den nahm mir Gott, ich sah ihn sterben, Dem Glück bezahlt' ich meine Schuld.

Drum, willst du dich vor Leid bewahren, So flehe zu den Unsichtbaren, Daß sie zum Glück den Schmerz verleihn. Noch keinen sah ich fröhlich enden, Auf den mit immer vollen Händen Die Götter ihre Gaben streun.

Und wenn's die Götter nicht gewähren, So acht' auf eines Freudes Lehren Und rufe selbst das Ünglück her, Und was von allen deinen Schätzen Dein Herz am höchsten mag ergötzen, Das nimm und wirf's in dieses Meer.«

Und jener spricht, von Furcht beweget: $»$ Von allem was die Insel heget, Ist dieser Ring mein höchttes Gut. Inh will ich den Erinnen weihen, Ob sie mein Glück mir dann verzeihen.« Und wirft das Kleinod in die Flut.

Und bei des nächtes Morgens Lichte Da tritt mit fröhlichem Gesichte Ein Fischer vor den Fürchten hin: Herr, diesen Fisch hab' ich gefangen, Wie keiner noch ins Netz gegangen, Dir zum Geschenke bring' ich ihn.

Und als der Koch den Fisch zeteilet, Kommt er bestürtzt herbeigeeilet, Und ruft mit hoch erstauntem Blick: »Sieh Herr, den Ring, den du getragen, Ihn fand ich in des Fischen Magen, $\mathrm{O}$ ohne Grenzen ist dein Glück!« 
Hier wendet sich der Gast mit Grausen:

»So kann ich hier nicht ferner hausen,

Mein Freund kannst du nicht weiter sein.

Die Götter wollen dein Verderben,

Fort eil' ich, nicht mit dir zu sterben.«

Und sprach's und schiffte schnell sich ein ${ }^{1}$.

\section{$O$ anel de Polícrates}

De pé, sobre as ameias do telhado,

Olhava, reflectindo deleitado,

Para Samos, a ilha dominada.

Sob a minha alçada, está tudo isto,

Começou a interpelar o rei do Egipto,

Sou feliz, deves concordar.

Obtiveste o favor dos deuses!

Que teus iguais foram antes,

Agora dá poder ao teu ceptro.

Mas vive ainda alguém para o vingar,

Feliz não te posso considerar,

Enquanto o inimigo estiver desperto.

E ainda antes que o rei acabasse,

Enviado de Mileto, apresentou-se

Um embaixador ao tirano:

Deixa, Senhor! subir os sacrificiais odores,

E, com ramos de viçoso loureiro,

Coroa festivamente o teu cabelo.

Surpreso, o teu inimigo caiu pela lança,

Com a notícia alegre, envia-me

Polidoro, o teu fiel comandante -

E retira de uma bacia negra,

Para terror de ambos, ainda ensanguentada,

Uma cabeça assaz conhecida porquanto.

1 Friedrich Schiller, Sämtliche Gedichte und Balladen, herausgegeben von Georg Kurtscheid, Franfurt am Main, Insel Verlag, 2004, pp. 65-67. 
O rei deu um passo atrás, com terror:

Então, a contar com a sorte te advirto,

Replica com apreensivo olhar.

Pensa na onda traiçoeira,

Como facilmente a tempestade naufraga,

Assim, a sorte dúbia da tua frota pode pairar.

E, ainda antes de estas palavras dizer,

Veio-o o júbilo interromper,

Que, regozijando, no ancoradouro, ecoa.

Carregado ricamente com estranhos tesouros,

Às costas da pátria regressa o barco,

Qual floresta de mastros de madeira.

O convidado real fica surpreendido:

A tua sorte está hoje em boa medida,

Mas toma cuidado com a sua insegurança.

Os exércitos dos cretenses, em armas,

Com perigo de guerra te ameaçam,

Já desta praia se acercam.

E ainda mal estas palavras proferira,

Nos barcos, um fervilhar se observa,

E mil vozes gritam: Vitória!

Do inimigo estamos livres,

A tempestade destruiu os cretenses,

Findou, terminada está a guerra.

Com terror, o convidado escutou isto:

Sem dúvida, devo-te considerar feliz,

Contudo, disse, temo pela tua ventura.

Dos deuses receio a inveja,

A alegria da vida sem mistura

Jamais foi reservada a mortal algum. 
A mim, tudo é também bem aconselhado,

Em todos os meus régios actos,

Acompanha-me a graça divina,

Tive uma herança cara, no entanto,

Vi-o morrer, Deus levou-mo,

Paguei com a culpa a minha sina.

Por isso, se do desgosto te quiseres prevenir,

Então, suplica aos Invisíveis,

Para que, com a dor, te concedam a sorte.

Nunca vi ninguém terminar feliz,

Quem os deuses de mão cheia,

Com os seus dotes sempre favoreceram.

E o outro, movido pelo medo, retorquiu:

De tudo o que guarda esta ilha,

Este anel é o meu bem mais precioso.

Consagrá-lo-ei às Erínias,

Para que a minha felicidade perdoem.

E lança à maré-cheia a jóia.

E, na luz da manhã seguinte,

Veio, de alegre semblante,

Um pescador ter com o príncipe:

Senhor, apanhei este peixe,

Como nunca outro na rede apanhei,

Trago-to como presente.

E quando partiu o peixe, o cozinheiro,

Perturbado, a toda a pressa, veio

E gritou, com o olhar muito admirado:

«Vê, Senhor, o anel que trazias

No buxo do peixe o achei,

Oh, sem limites é a tua felicidade!»

Então, voltou-se, com terror, o hóspede:

«Assim, aqui não ficar mais não posso,

Não podes continuar a ser meu amigo. 
Querem-te destruir os deuses,

Vou depressa, para contigo não morrer.»

E, dizendo isto, a toda a pressa embarcou.

Tradução de Maria do Sameiro Barroso

Digo palavras compreensíveis para quem pensa.

Imaculado é o céu profundo.

Baquílides $^{2}$

Schiller escreveu esta balada em Junho de 1797. Não lhe faz qualquer referência na correspondência que trocava, sobretudo com Goethe, nesse período.

O tema da balada reporta-se a Polícrates, que se tornou senhor da Ilha de Samos, no Egeu, em 538 e que foi morto pelo sátrapa persa Oretes, em 523/522 a.C. O rei do Egipto é Amásis, um rei da 26 ${ }^{\mathrm{a}}$. Dinastia (570-526 a.C. $)^{3}$.

Embora Schiller não tenha feito referência a esta balada, deduz-se, facilmente, que a fonte em que se baseou foi Heródoto ${ }^{4}$.

À fonte terá acrescentado a sua fantasia: durante a encenação da ameaça de guerra, a entrega da cabeça do inimigo e o nome de Polidoro não são mencionados por Heródoto. Este historiador narra com pormenor o sucesso de Polícrates. A apreensão, motivada por este sucesso, é manifestada de forma amiga por Amásis, numa carta.

Schiller encena o encontro de ambos, durante uma visita de Amásis à ilha de Samos, na qual o tirano se vangloria, envaidecido, pelo seu poder e pela sua desmedida sorte, acentuando o dramatismo que esta escalada encerra. Amásis assiste, cada vez mais aterrorizado, à sorte de Polícrates, que este encara com a maior naturalidade, parecendo querer ignorar que toda a sorte possui o seu reverso.

2 Baquílides, Ode III, vv. 85-86, in Poesia Grega de Álcman a Teócrito, Tradução de Frederico Loutrenço, Lisboa, Livros Cotovia, 2006, p. 83.

3 Friedrich Schiller, Gedichte, Auswahl und Anmerkungen von Norbert Oellers, Stuttgart, Phillip Reclam jun., 2001, p. 170.

${ }^{4}$ Heródoto, Histórias, livro $3^{\circ}$, Introdução, versão do grego e notas de Maria de Fátima Silva e de Cristina Abranches, Lisboa, Edições 70, pp. 69-73. 
Polícrates era efectivamente:

um soberano todo-poderoso, a viver no auge de uma prosperidade que o convidava a todas as temeridades e excessos. Conquistar, dominar, possuir eram os seus objectivos únicos, estimulados por um sucesso que a tudo se sobrepunha. Crescia, portanto, Polícrates pelo caminho cómodo do êxito. $O$ alerta chegou-lhe através da mensagem amiga de Amásis do Egipto, aqui no papel do conselheiro sensato, que o incentivou a alterar o curso suave de uma felicidade permanente, autoflagelando-se sob a forma da privação de algo que lhe fosse querido. Mas a mera simulação de se privar do poder, sob a forma de um anel real lançado ao mar, em nada alterou a realidade nem desviou a marcha monótona do sucesso. Polícrates rejubilou com a devolução do seu anel e, com ele, da sua autoridade incólume; não compreendeu o verdadeiro significado de um sinal que os deuses, por vias diversas, the comunicaram ${ }^{5}$.

E Schiller termina a sua balada, com a partida abrupta de Amásis, que, de tão amedrontado, receou que a vingança divina também se pudesse abater sobre ele; tendo deixado Polícrates à beira dos cegos precipícios, nos quais a sorte, que o fazia ignorar todos os perigos, o conduziu até Oretes, que ao chegar à Magnésia, de forma atroz o empalou ${ }^{6}$.

Polícrates tinha esquecido que:

Há um castigo dos deuses.

Feliz quem, tranquilo,

acaba o seu dia sem lágrimas ${ }^{7}$.

MARIA DO SAMEIRO BARROSO

5 Maria de Fátima Silva e Cristina Abranches, Introdução a Heródoto, Histórias, livro $3^{\circ}$, pp. 37-38.

${ }^{6}$ Heródoto, Histórias, livro $3^{\circ}$, p. 152.

7 'Álcman', in Maria Helena da Rocha Pereira, Hélade, Faculdade de Letras, Universidade de Coimbra, Instituto de Estudos Clássicos, 1990, p. 99. 